\title{
Effects of hemocoagulase agkistrodon on the coagulation factors and its procoagulant activities
}

This article was published in the following Dove Press journal:

Drug Design, Development and Therapy

\section{Haixin $\mathrm{Li}^{1}{ }^{1, *}$ \\ Ying Huang ${ }^{2, *}$ \\ Xian $\mathrm{Wu}^{3}$ \\ Ting $\mathrm{Wu}^{\prime}$ \\ Ying $\mathrm{Cao}^{\prime}$ \\ Qimei Wang' \\ Yuchang Qiu' \\ Weiming $\mathrm{Fu}^{\prime}$ \\ Qun Zhang ${ }^{4}$ \\ Jianxin Pang'}

'Guangdong Provincial Key Laboratory of New Drug Screening, School of Pharmaceutical Sciences, Southern Medical University, Guangzhou,

People's Republic of China;

${ }^{2}$ Department of Pharmacy, Shenzhen

Hospital, Southern Medical University,

Shenzhen, People's Republic of

China; ${ }^{3}$ Department of Pharmacy, The

Third Affiliated Hospital, Southern

Medical University, Guangzhou,

People's Republic of China; ${ }^{4}$ Good

Clinical Practice Development, The

Third Affiliated Hospital, Southern

Medical University, Guangzhou,

People's Republic of China

*These authors contributed equally to this work

\begin{abstract}
Objective: Hemocoagulase agkistrodon (HCA), a thrombin-like enzyme (TLE) from the venom of the Chinese moccasin snake (Deinagkistrodon acutus), has been used in clinical practice as a hemostatic compound. The aim of this study was to further investigate the pharmacological properties of HCA.
\end{abstract}

Materials and methods: Sodium dodecyl sulfate or native polyacrylamide gel electrophoresis (SDS- or N-PAGE) as well as enzyme linked immunosorbent assays (ELISAs) were conducted to study the effects of HCA on the human plasma fibrinogen and prothrombin levels, as well as its in vitro interactions with some coagulation factors. In addition, the bleeding time effects of HCA in the mouse tail-bleeding model as well as its effects on the fibrinogen levels in rabbits were determined in vivo.

Results: In vitro results revealed that HCA exerts its procoagulant activities by hydrolyzing fibrinogen into segments that are easier to be absorbed, reducing the risk of thrombus formation. Besides, HCA could significantly inhibit the activation of prothrombin at the concentration of $0.3 \mu \mathrm{M}$. Unexpectedly, we also found that HCA was able to strongly bind to factor $\mathrm{X} / \mathrm{Xa}$ (in a ratio of 1:1) and thus inhibit the acceleration of active factor $X$ to tissue plasminogen activatorcatalyzed plasminogen activation, demonstrating that it could be less likely to lead to thrombus formation. Finally, in vivo results indicated that HCA could significantly shorten the bleeding time in the mouse tail-bleeding model and had no effect on the fibrinogen levels in rabbits.

Conclusion: In summary, HCA, a unique and new family member of TLEs, may become a new clinical drug for the prevention and treatment of hemorrhage due to its unique and complex interactions with the blood system. Clarification of these features will enable us to further understand the mechanism of action of HCA and then promote its further application in clinical practice as a therapeutic drug.

Keywords: thrombin-like enzymes, TLEs, coagulation factors, procoagulant activity, anticoagulant activity, FXa, t-PA

\section{Introduction}

Surgical operation or trauma not only increases blood loss, but also complicates the surgical process, thus administration of effective hemostatic drugs is a prerequisite for performing safe operations. ${ }^{1,2}$ It is generally recognized that a balance between coagulation and anticoagulation is required for proper functioning of the blood clotting system, which is key to maintain the normal body blood flow and prevent blood loss. ${ }^{3}$ The normal coagulation process in the body mainly depends on the structure and functions of the intact blood vessel wall, the quality and quantity of platelets, the normal activity of plasma coagulation factors, and the complex molecular regulation involved in the whole process. ${ }^{4}$ The coagulation process is generally divided into endogenous coagulation, exogenous coagulation, and coagulum formation processes. ${ }^{5}$ 
The endogenous coagulation pathway refers to the blood coagulation process, which involves all the blood factors. When the vessel wall is damaged, the subcutaneous tissues are exposed, and the negatively charged subcutaneous collagen fibers come in contact with the coagulation factors. Then factor X (FX) activator complexes can be formed after a series of reactions with the factor XII (FXII) collagen, the collagen releasing enzyme, calcium ions, and platelet phospholipids. The exogenous coagulation pathway refers to the blood coagulation process which includes coagulation factors all of which are not present in the blood. This process is initiated from the exposure of tissue factors (TFs) to blood in order to form FX activator complexes. When tissue is damaged, the released TFs together with the participation of calcium ions can form FX activator complexes with active factor VIIa (FVIIa) and platelet phospholipids. Both endogenous and exogenous coagulation processes can activate the "final common pathway" of FX, which leads to thrombin and fibrin formation.

At present, traditional hemostatic drugs can achieve good hemostatic effects, but at the same time their application has many drawbacks. ${ }^{6}$ For example, complications are often observed during the treatment with drugs inhibiting the fibrinolysis system. Besides, the hemostatic drugs can have negative effects on patients with coagulation factor deficiency. Consequently, several snake venoms containing a variety of protein components affecting the body's coagulation process have emerged..$^{7-12}$ Among them, a class of serine proteases, often called TLEs, can act directly on fibrinogen to release FPA, such as batroxobin, ancrod, flavoxobin, and bothrombin, FPB, such as contortrixobin and okinaxobin, or FPAB, such as russelobin, resulting in the polymerization of fibrin monomers, coagulation, or acting as defibrase. ${ }^{13,14}$ TLEs are animal-derived protease hemostats which have drawn great attention due to their outstanding features of low toxicity, fast onset of action, long-lasting efficacy, and no intravascular embolism. Since the first coagulation studies on reptilase in $1957,{ }^{15}$ the primary structures of more than 40 TLEs have been elucidated, most of which are composed of single-chain glycoproteins consisting of more than 200 amino acid residues. ${ }^{16-18}$ In addition, a large number of structurally different snake venom proteins, such as acutobin, acutin, and acuthrombin, have been isolated and purified. ${ }^{19-23}$ In early 1998, a new active ingredient-with hemostatic activity, called hemocoagulase agkistrodon (HCA), was isolated from Agkistrodon acutus venom and purified. After extensive research and development, in 2009 the ingredient was approved to be listed in a class of national new drugs (Hemocoagulase Agkistrodon for Injection, named as HCA).
Our preliminary studies (unpublished data) have shown that the hemostatic mechanism of HCA is to promote FPA release from fibrinogen without activating factor FXIII (FXIII). Only one peptide fragment of fibrinogen is cleaved by HCA to form the fibrin monomers, and these monomers are polymerized into soluble fibrin polymers by non-covalent cross-linking, thus HCA exerts a hemostatic effect without leading to thrombus formation. Unlike other traditional congeners such as batroxobin and hemocoagulase, HCA contains only a single thrombin-like component and does not contain active factor $\mathrm{X}(\mathrm{FXa})$. The absence of $\mathrm{FXa}$ reduces the risk of thrombotic adverse reactions, since FXa normally plays a decisive role in the production and formation of thrombin, which may lead to thrombosis. Another advantage of HCA not activating coagulation FXIII is that it produces a higher concentration of soluble fibrins by its intravascular action, thereby accelerating hemostasis at the wound site but without causing aggregation of insoluble fibrin complexes by re-cross-linking between the fibrins molecules. As a result, thrombosis is prevented in the normal blood vessels.

Clinically, HCA injection is widely used to prevent clotting in the local area of superficial wound bleeding during surgical operations. ${ }^{24,25}$ However, the mechanisms of function of HCA and its potential to be applied worldwide in clinical practice need to be further studied. Therefore, following our previous research and in order to promote the application of HCA in clinical practice, we further studied the mechanism of action of HCA and its effects on coagulation factors and their functions.

\section{Materials and methods \\ Reagents}

HCA (Beijing, Konruns Pharmaceutical Co., Ltd.); DEAESepharose Fast Flow and Sephadex-G25 were obtained from Amersham Biosciences (Uppsala, Sweden); peroxidase-conjugated goat anti-rabbit IgG was purchased from BoaoBioTech (Beijing, People's Republic of China); human fibrinogen, FPA, FPB, phenylmethanesulfonyl fluoride (PMSF), egg-yolk L- $\alpha$ phosphatidylcholine, and bovine brain L- $\alpha$-phosphatidylserine were from Sigma-Aldrich Co. (St Louis, MO, USA); human prothrombin (FII), thrombin, active factor V (FVa), FVII/ VIIa, factor IX (FIX)/IXa, and FX/Xa were purchased from Hematologic Technologies (Burlington, VT, USA); the chromogenic substrate H-D-Phe-Pip-Arg-pNa-2 $\mathrm{HCl}$ (S2238) was from Hyphen BioMed (Neuville-Sur-Oise, France); rabbit anti-HCA polyclonal antibodies were prepared in our laboratory as described in Supplementary materials ${ }^{26}$ (section "The preparation of polyclonal antibody") and its ELISA titer was above $1: 1,000,00$. The specificity of polyclonal antibodies was 
confirmed by Western blot analysis (data not shown). All other chemicals and reagents were of the purest grade available.

\section{In vitro study}

\section{Biochemical properties of HCA}

Effect of $\mathrm{pH}$ on the coagulation activity of HCA

HCA was dissolved in buffer solutions with $\mathrm{pH}$ values ranging from 4 to 9 . Then, $0.2 \mathrm{~mL}$ of each HCA solution $(8 \mathrm{U} / \mathrm{mL})$ was mixed with $0.2 \mathrm{~mL}$ of ox plasma. Coagulometer was used to determine the optimum $\mathrm{pH}$ by measuring the clotting time of the mixtures.

Effect of temperature on the coagulation activity of HCA One milliliter of HCA solution and $1 \mathrm{~mL}$ of ox plasma were incubated for $3 \mathrm{~min}$ at different temperatures $\left(20^{\circ} \mathrm{C}-50^{\circ} \mathrm{C}\right)$ before mixing in the tube. Clotting time of the mixtures was recorded when the solution became cloudy, at which point the optimum temperature was determined.

\section{Effect of $\mathrm{Ca}^{2+}$ concentration on the coagulation activity of HCA}

Solutions containing $8 \mathrm{mg} / \mathrm{mL}$ of human fibrinogen and $1 \mathrm{U} / \mathrm{mL}$ of HCA were prepared with injection water and then $100 \mu \mathrm{L}$ of each solution was taken and mixed. After incubation for $3 \mathrm{~min}, 20 \mu \mathrm{L}$ of different concentrations of $\mathrm{CaCl}_{2}$ solutions was added into $200 \mu \mathrm{L}$ of mixture, making the final concentration of $\mathrm{CaCl}_{2}$ in the solutions to be in the range of $0.45-9.0 \mathrm{mM}$. The clotting time of each mixture was tested to measure the influence of $\mathrm{Ca}^{2+}$ on the clotting time of the fibrinogen mediated by HCA.

\section{Effect of PMSF on the release activity of fibrinopeptide mediated by HCA}

Fibrinogen solution (1\%) and $35 \mathrm{~g} / \mathrm{mL}$ of HCA were individually prepared with physiological saline. PMSF was dissolved in isopropanol at various concentrations $(0-100 \mu \mathrm{M})$. Physiological saline $(10 \mu \mathrm{L})$, isopropanol, and various concentrations of PMSF were added into tubes. Then, $200 \mu \mathrm{L}$ of HCA was added into each tube, and the tubes were incubated for $5 \mathrm{~min}$ at $37^{\circ} \mathrm{C}$. Subsequently $200 \mu \mathrm{L}$ of fibrinogen solution was added into each tube, and immediately followed by clotting time counting while shaking the tubes gently in a water bath at $37^{\circ} \mathrm{C}$.

\section{Hydrolysis of the fibrinogen from human standard plasma mediated by HCA}

HCA $(20 \mu \mathrm{g} / \mathrm{mL})$ and human thrombin $(8 \mathrm{U} / \mathrm{mL})$ solutions were individually prepared with $0.05 \mathrm{~mol} / \mathrm{L}$ Tris- $\mathrm{HCl}$ buffer ( $\mathrm{pH} 7.4$ ), and the prepared solutions were incubated in a water bath at $37^{\circ} \mathrm{C}$. Seven EP tubes $(2 \mathrm{~mL})$ were used and numbered from 1 to 7 and then the solution was added as follows: $0.25 \mathrm{~mL}$ of human plasma was aliquoted into each tube, and $0.25 \mathrm{~mL}$ of $0.05 \mathrm{~mol} / \mathrm{L}$ Tris- $\mathrm{HCl}$ buffer ( $\mathrm{pH} 7.4$ ) was added to tube 1 , $0.25 \mathrm{~mL}$ of $4 \mathrm{U} / \mathrm{mL}$ HCA solution was added to tubes $2-6$, and $0.25 \mathrm{~mL}$ of $8 \mathrm{U} / \mathrm{mL}$ human thrombin solution was added to tube 7 . All tubes were mixed and then individually incubated. Tubes 1 and 7 were incubated for $16 \mathrm{~h}$, while tubes 2-6 were incubated for $1,4,8,12$, and $16 \mathrm{~h}$, respectively, in a water bath at $37^{\circ} \mathrm{C}$. After incubation, the samples were centrifuged, the supernatant was discarded, and the clots were rinsed with adequate $0.15 \mathrm{M} \mathrm{NaCl}$ solution. Following this, $0.5 \mathrm{~mL}$ of $5 \mathrm{~mol} / \mathrm{L}$ urea solution $(2 \% \mathrm{SDS}, 2 \% \beta$-mercaptoethanol, $0.1 \mathrm{M}$ sodium phosphate, $\mathrm{pH}$ 7.15) was added in each tube, and then the tubes were vigorously shaken to dissolve the clot. The abovementioned reaction was repeated by adding $5 \mu \mathrm{L}$ of $0.8 \mathrm{M} \mathrm{CaCl}_{2}$ solution to each of the previously mentioned reaction systems. The sample and sodium dodecyl sulfate polyacrylamide gel electrophoresis (SDS-PAGE) sample loading buffer were mixed in a ratio of $4: 1$ and boiled for 3-5 min after the fibrinogen clot was dissolved. Finally, $10 \mu \mathrm{L}$ of the sample was tested by native PAGE (N-PAGE).

\section{Binding affinity of HCA to coagulation factors}

N-PAGE was chosen for its advantage to maintain the functional properties of the separated proteins and its high efficiency in protein separation and identification. The binding affinities of HCA to the coagulation factors FX/FXa, FIX/ active factor IX (FIXa), FVII/FVIIa, and FII were analyzed by N-PAGE as follows. HCA $(24 \mu \mathrm{M})$ and FX/FXa, FIX/ FIXa, FVII/FVIIa, and FII $(16 \mu \mathrm{M})$ were prepared by mixing with $0.05 \mathrm{~mol} / \mathrm{L}$ Tris-HCL (pH 7.4, containing $0.1 \mathrm{M} \mathrm{NaCl}$, $1 \mathrm{mM} \mathrm{CaCl}_{2}$ ). A certain amount of solution was taken out and used for N-PAGE after $90 \mathrm{~min}$ of incubation at $37^{\circ} \mathrm{C}$. Then, $1 \mathrm{mM}$ of $\mathrm{Ca}^{2+}$ was individually added into each sample solution, $0.05 \mathrm{~mol} / \mathrm{L}$ Tris-HCL ( $\mathrm{pH} 7.4$, containing $0.1 \mathrm{M}$ $\mathrm{NaCl}, 1 \mathrm{mM} \mathrm{CaCl}_{2}$ ) buffer, and separating and stacking gels, to assure adequate $\mathrm{Ca}^{2+}$ concentration.

To investigate the molecular proportion between HCA and the coagulation factors in the formed complexes, HCA $(16 \mu \mathrm{M}), \mathrm{FX} / \mathrm{FXa}$, and FIX/FIXa $(16 \mu \mathrm{M})$ were used. The samples were prepared as described earlier.

In order to quantify the binding affinity of HCA to the abovementioned factors, an ELISA method was applied. First, $10 \mathrm{nM}$ of FX, FIX, FVII, and FII solutions were prepared with Tris- $\mathrm{HCl}$ coating buffer $(0.1 \mathrm{M}, \mathrm{pH} 8.8)$, and the wells in the microtiter plate were coated with the corresponding solutions. Second, HCA at various concentrations was added into the wells. Third, polyclonal antibody and secondary antibodies were added. A chromogenic substrate 
was used, and the values at $\mathrm{OD}_{450}$ were measured for affinity detection.

\section{Effect of HCA on the Fll complex}

FX/FXa and FIX/FIXa are vital parts of FII complexes and the complexes of endogenous and exogenous FX activators. Binding between HCA and those factors can influence the function of the factors, thus inhibiting the complexes mentioned earlier. PCPS (prepared according to the procedure of Higgins and $\mathrm{Mann}^{27}$ and the detailed protocol is given in Supplementary materials under the section "The preparation of PCPS") were used to investigate the effects of HCA on the FII complexes. FII complex solutions were prepared with assay buffer (containing 0.02 M HEPES, 0.15 M NaCl, $5 \mathrm{mM} \mathrm{Ca}^{2+}, \mathrm{pH}$ 7.4). Mixtures of $\mathrm{FXa}(3 \mathrm{nM})$ and HCA $(15 \mathrm{nM}, 60 \mathrm{nM}, 0.3 \mu \mathrm{M})$ were incubated for $30 \mathrm{~min}$ at $37^{\circ} \mathrm{C}$ and then mixtures of FII $(1.4 \mu \mathrm{M}), \mathrm{FVa}(20$ $\mathrm{nM})$, and PCPS $(40 \mu \mathrm{M})$ were added. The reactions were set up at $30^{\circ} \mathrm{C}$ and then $100 \mu \mathrm{L}$ of each sample was removed after $2,10,20,30,40,50,60,80$ and $100 \mathrm{~min}$ of incubation. EDTA (50 $\mathrm{mM})$ was added to terminate the reactions. Then, $1 \mu \mathrm{M}$ of chromogenic substrate (S2238) was added, and $\mathrm{OD}_{405}$ values were measured. The amount and activation extent (percentage) of FIIa (thrombin) at various time points were calculated.

\section{ELISA for detection of tissue plasminogen activator (t-PA) hydrolysis by HCA}

Solutions of $60 \mathrm{nM}$ of HCA (or ancrod and batroxobin) and $60 \mathrm{nM}$ of t-PA were mixed and incubated in a water bath at $37^{\circ} \mathrm{C}$. Then $10 \mu \mathrm{L}$ of reaction solution was removed at 0,5 , $10,20,30,40,50,60,120,240$ and $480 \mathrm{~min}$, and $200 \mu \mathrm{L}$ of specific chromogenic substrate containing S2408 and EDTA $(50 \mathrm{mM})$ was added into each solution. After $2 \mathrm{~min}$, the $\mathrm{OD}_{405}$ values were determined.

To study the effects of HCA on the plasminogen activation by binding to FXa, the HCA $(0.2 \mu \mathrm{M}) / \mathrm{FXa}(0.1 \mu \mathrm{M})$ or ancrod $(0.6 \mu \mathrm{M}) / \mathrm{FXa}(0.1 \mu \mathrm{M})$ mixtures were incubated in a water bath at $37^{\circ} \mathrm{C}$ for $15 \mathrm{~min}$. First, $130 \mu \mathrm{L}$ of PCPS solution and then $130 \mu \mathrm{L}$ of Lys-plasminogen solution $(0.5 \mu \mathrm{M})$ were added. After incubation for $25 \mathrm{~min}$ at $22^{\circ} \mathrm{C}, 130 \mu \mathrm{L}$ of $10 \mathrm{nM}$ $\mathrm{t}-\mathrm{PA}$ solution was added and the mixture was incubated at $22^{\circ} \mathrm{C}$. Afterward, $50 \mu \mathrm{L}$ of the reaction solution was transferred into a 96-well plate at different time points. Finally, $200 \mu \mathrm{L}$ of the chromogenic liquid was added, and the $\mathrm{OD}_{405}$ values were determined.

\section{In vivo study}

\section{Animals}

Kunming mice (KM; license number: SYXK [Guangdong] 2006-0074) and New Zealand white rabbits (license number:
SYXK [Guangdong] 2008-0002) were obtained from the Animal Experiment Center of Southern Medical University, People's Republic of China. The animals were fed adaptively for 7 days before experiments, where light and environment were controlled for $12 \mathrm{~h}$ light and $12 \mathrm{~h}$ dark cycles, while animals were provided with access to food and water. The room temperature was controlled for $23^{\circ} \mathrm{C}-28^{\circ} \mathrm{C}$ and the humidity was controlled for $40 \%-60 \%$. The procedures for care and use of animals were approved by the Ethics Committee of Southern Medical University, and all applicable institutional and governmental regulations concerning the ethical use of animals were followed.

\section{Mouse tail-bleeding model}

HCA ( $\mathrm{n}=10$ per dose group) or a control was intravenously injected $30 \mathrm{~min}$ before the mouse tails (non-anesthetized KM mice) were transected at a distance of $4 \mathrm{~mm}$ from the tip. The blood lost from the tail was continually absorbed with filter papers until the tail stopped bleeding. The time until continuous blood flow ceased for $>10 \mathrm{~s}$ was recorded. In addition, $0.25 \mu \mathrm{g} / \mathrm{kg}$ of HCA was replaced by $0.5 \mathrm{kU} / \mathrm{kg}$ reptilase (Solco Basle Ltd, Basle, Switzerland) as a positive control.

\section{The determination of changes in fibrinogen levels after dosing}

Indwelling needles were implanted into the arteria auricularis of the New Zealand rabbits ( $\mathrm{n}=6$ per group) mentioned earlier. Whole blood was drawn pre-dose administration and then corresponding drugs were injected into the ear vein. Then $1 \mathrm{~mL}$ of whole blood was individually drawn post-dose administration $(0.5,1,2,4$, and $6 \mathrm{~h})$. Sodium citrate hydrochloride was added into the blood as an anticoagulant. Plasma was collected after centrifugation of the blood at 3,000 rpm for $15 \mathrm{~min}$. Finally, the concentrations of fibrinogen were measured according to the method described in the kit's manual.

\section{Statistical analyses}

All results were expressed as mean \pm SEM. GraphPad Prism 5 was used for analyzing the data. Student's $t$-test was used to evaluate differences between groups. Differences between groups were assumed significant when $p$-values were $<0.05$.

\section{Results}

\section{In vitro study}

Biochemical properties of HCA

As shown in Figure 1A, the best $\mathrm{pH}$ value for the optimal relative activity of HCA was determined to be 5.5, which 
A

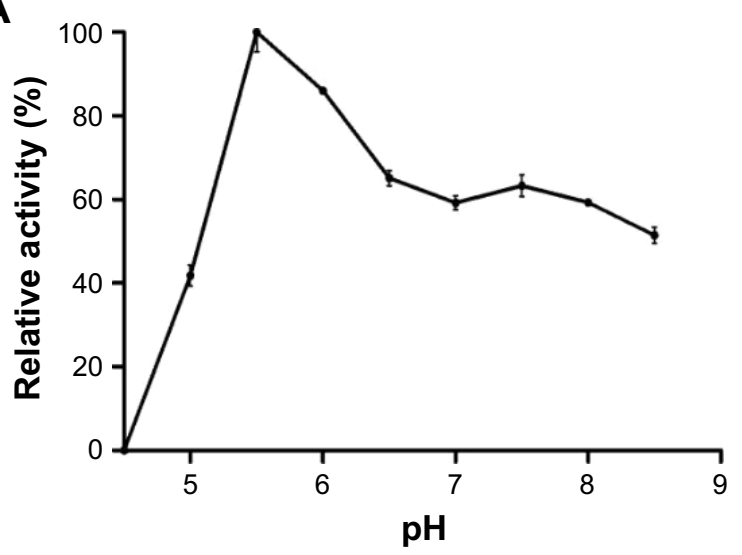

C

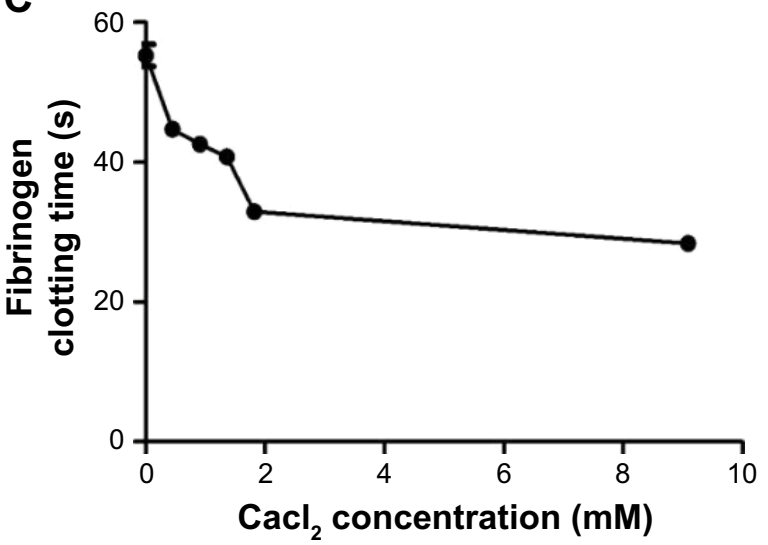

B

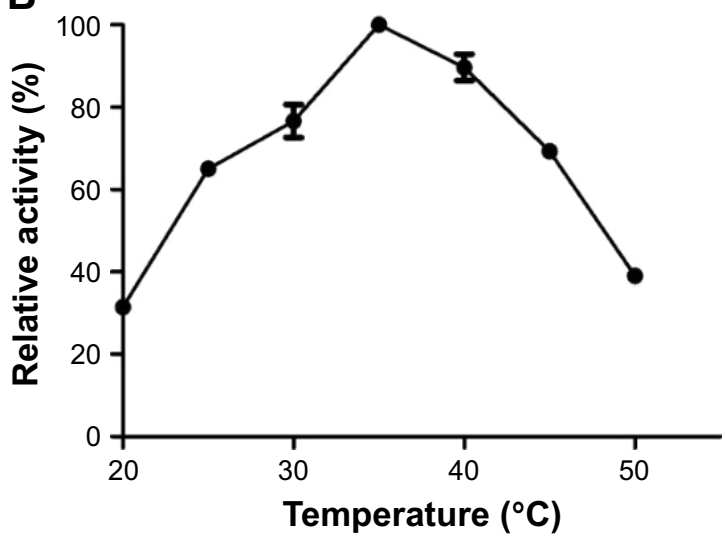

D

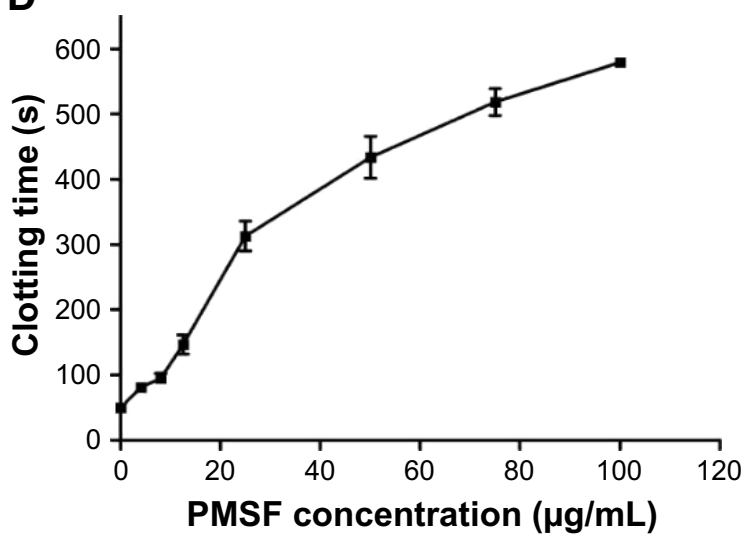

Figure I Biochemical properties of HCA. (A) Activity-pH relationship curve; (B) activity-temperature relationship curve; (C) effects of Ca ${ }^{2+}$ on the fibrinogen clotting activity; (D) effect of PMSF on the clotting time of fibrinogen solution after the addition of HCA. The values shown are the mean values \pm SEM ( $n=3$ ).

Abbreviations: HCA, hemocoagulase agkistrodon; PMSF, phenylmethanesulfonyl fluoride; SEM, standard error of mean.

was in agreement with the result of defibrase extracted from Cordyceps militaris. ${ }^{28}$ Besides, the optimal temperature was determined to be $35^{\circ} \mathrm{C}$, and its activity was relatively stable between $35^{\circ} \mathrm{C}$ and $40^{\circ} \mathrm{C}$ (Figure $1 \mathrm{~B}$ ). In addition, we found that with the increasing concentration of $\mathrm{Ca}^{2+}$ ions, the clotting time was shortened, which suggested that $\mathrm{Ca}^{2+}$ affects the coagulation function of HCA (Figure 1C). As expected, the HCA activity on fibrinogen clotting was markedly inhibited by PMSF in a concentration-dependent manner (Figure 1D), but heparin and EDTA did not influence the activity (data not shown), which indicates that the active site of HCA involves a serine residue, like in other TLEs, suggesting that HCA is a snake venom serine protease. ${ }^{29}$

\section{Effects of HCA on the hydrolysis of the fibrinogen from standard human plasma}

Human plasma coagulation was applied to simulate the coagulation environment in vivo. It was speculated that the fibrin monomers formed by HCA during the hemostasis process may form covalent cross-linkage within the $\gamma$-chains, in the absence (Figure $2 \mathrm{~A}$ ) or presence of $\mathrm{Ca}^{2+}$ ions (Figure 2B), making it easier for the clot to be dissolved. Consequently, thrombus formation would be prevented under the strong hemostatic effect of HCA. At the same time, this experiment also showed that, at the presence of appropriate $\mathrm{Ca}^{2+}$ ion concentrations, the procoagulation effect of HCA can be improved (Figure 2B).

\section{The binding of HCA to coagulant factors}

We further studied the influence of HCA on blood coagulation factors and their functions, to investigate further the mechanism of hemorrhage prevention by HCA. Curiously, we observed that HCA was able to bind to FX. This suggested that HCA was also able to bind to other vitamin K-dependent clotting factors (II, VII, IX, X). Therefore, the binding activities of HCA to other human vitamin K-dependent clotting factors (II, VII, IX, X) were determined by N-PAGE. The results are shown in Figure 3A. When HCA was incubated with FX or factor IX, new bands, with higher molecular weight than the bands of substrates, were observed, which indicated that HCA had formed complexes with FX and factor IX. However, in the mixtures of HCA 

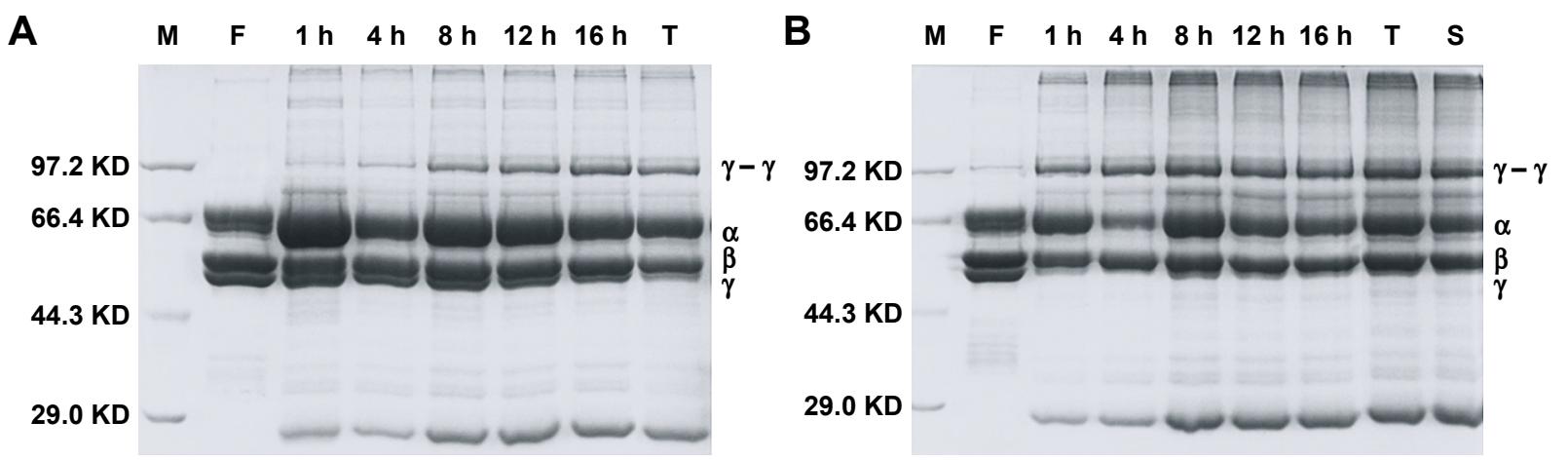

Figure 2 Hydrolysis of HCA to fibrinogen from human standard plasma with time-course analysis by SDS-PAGE in the absence (A) or presence (B) of Ca ${ }^{2+}$ ( I0\% acrylamide gels). Lane M: PMW markers; Lane F: fibrinogen solution for 16 h; Lanes I-16 h: fibrinogen from human standard plasma hydrolyzed by HCA for I, 4, 8, I2, and I6 h; Lane S: standard protein with $\beta$ and $\gamma$ fragment; Lane T: fibrinogen from human standard plasma hydrolyzed by thrombin for 16 h; $\alpha, \beta$, and $\gamma$ stand for the three subunit bands of fibrinogen. Abbreviations: HCA, hemocoagulase agkistrodon; PMW, molecular weight of standard protein; SDS-PAGE, sodium dodecyl sulfate polyacrylamide gel electrophoresis.

with factor VII or FII, only two bands (Figure 3A) were detected on the N-PAGE, corresponding to the band of HCA and coagulant factors, respectively, demonstrating that a complex could not be formed under the same conditions.
To analyze the stoichiometry of HCA and the coagulation factor in the complex, the mixtures of HCA and FX or factor IX (molar ratio, 1:1) were subjected to N-PAGE. As shown in Figure 3B, only one band was observed, and the bands
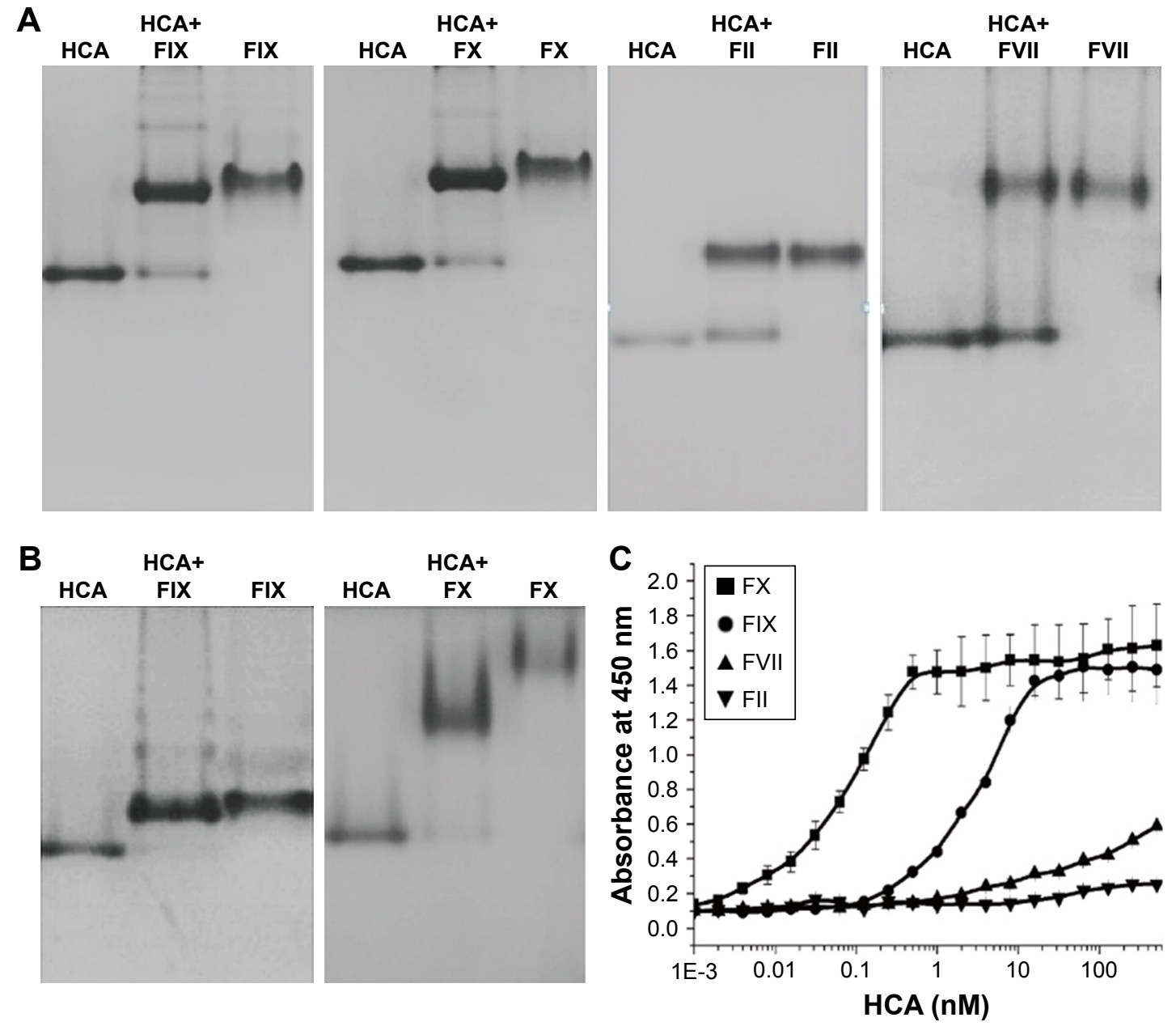

Figure 3 The binding of HCA to coagulant factors. (A) Analysis of the formation of a complex of HCA (0.24 $\mu$ M) with relative coagulant factors $(0.16 \mu \mathrm{M})$ in a ratio of I.5: I by N-PAGE. (B) Analysis of the formation of a complex of HCA $(0.16 \mu \mathrm{M})$ with FIX $(0.16 \mu \mathrm{M})$ or FX $(0.16 \mu \mathrm{M})$ in a ratio of I:I by N-PAGE. (C) Binding activities of HCA to solid-phase coagulation factors. The values shown are the mean values $\pm \operatorname{SEM}(n=3)$.

Abbreviations: FX, factor X; FIX, factor IX; FVII, factor VII; FII, prothrombin; HCA, hemocoagulase agkistrodon; N-PAGE, native polyacrylamide gel electrophoresis; SEM, standard error of mean. 
corresponding to substrates were absent on the gel. These results indicate that HCA could form a complex with FX or IX in a ratio of $1: 1$. However, HCA could not form a complex with factor VII or FII from human sources.

The affinity of HCA for binding to various solid-phase vitamin $\mathrm{K}$-dependent clotting factors (II, VII, IX, X) was further investigated by ELISA in the presence of $5 \mathrm{mM} \mathrm{Ca}^{2+}$ ions. As shown in Figure 3C, HCA bound to FX and FIX in a concentration-dependent manner. However, the extent of HCA binding to FVII was very low at the concentrations tested, and HCA did not bind to FII even at high concentrations (even at 100 times the concentration used for FX). Half-maximal binding of HCA to solid-phase human FX and FIX occurred at $0.08 \pm 0.007 \mathrm{nM}$ (mean \pm SEM, $\mathrm{n}=5$ ) and $3.00 \pm 0.20 \mathrm{nM}$ (mean $\pm \mathrm{SEM}, \mathrm{n}=5$ ), respectively, which showed that HCA could bind to FX with a higher affinity than with FIX.

\section{Effects of HCA on the activation of FII by prothrombinase}

When the wall of a blood vessel is damaged, FVIIa-tissue factor complex initiates coagulation by activating FX and FIX and by constituting prothrombinase (a complex of FII, FXa, FVa, phospholipids, and $\mathrm{Ca}^{2+}$ ), which leads to the formation of thrombin and ultimately a fibrin clot. ${ }^{30} \mathrm{FXa}$ plays an important role in the amplification of the coagulation cascade during the process of coagulation. On the basis of the abovementioned data, we hypothesized that HCA regulates its anticoagulant activity by binding to $\mathrm{FXa}$ and by inhibiting the activation of FII by prothrombinase. As shown in Figure 4, in the presence of $\operatorname{HCA}(0,15,60$, and

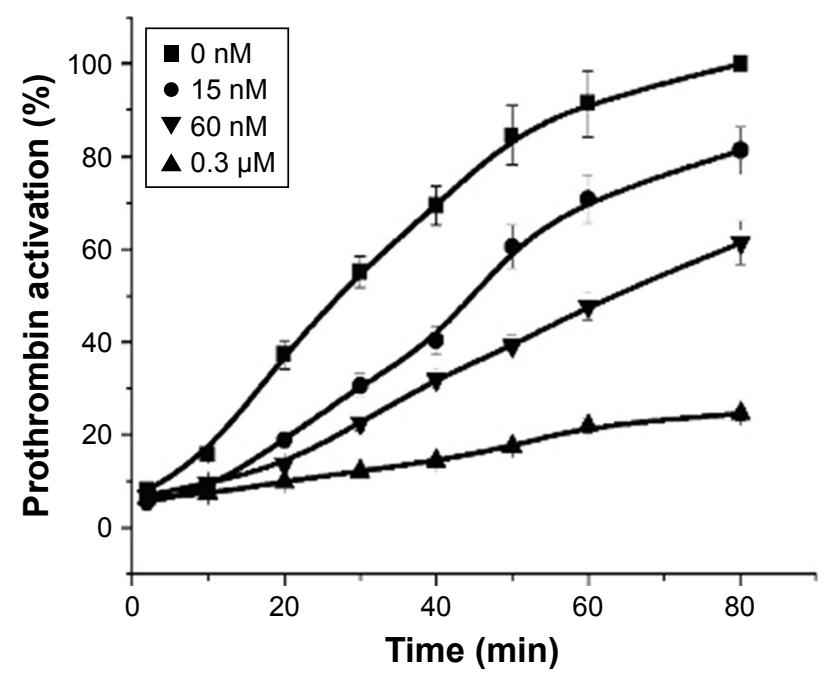

Figure 4 Influence of HCA on the activation of Fll by prothrombinase. The values shown are the mean values \pm SEM $(n=3)$.

Abbreviations: FII, prothrombin; HCA, hemocoagulase agkistrodon.
$0.3 \mu \mathrm{M})$, the capacity of prothrombinase to produce thrombin pronouncedly decreased in a dose-dependent manner and was almost completely inhibited by a 100 -fold molar excess of HCA to FXa. Apparently, the inhibition of prothrombinase by HCA is due to the binding of HCA to FXa (HCA could not activate FII in the follow-up studies [data not shown]), which probably indicates a potential anticoagulant activity of HCA in vivo.

\section{The indirect inhibitory effects of HCA on the acceleration of FXa to t-PA-catalyzed plasminogen activation}

FXa enhances the activation of the fibrinolysis zymogen plasminogen to plasmin by tissue plasminogen activator, ${ }^{31,32}$ and HCA is therefore likely to have an indirect influence on the fibrinolytic system by binding to FXa. The influence of HCA on the acceleration of FXa to t-PA-catalyzed plasminogen activation was determined by reconstituting a complex of plasminogen, FXa, t-PA, and phospholipids in vitro. The results in Figure 5A show that HCA, ancrod, and batroxobin have no effects on the activation of t-PA. As shown in Figure 5B, in the presence of HCA, the capacity of t-PAcatalyzed plasminogen to produce plasmin was decreased, indicating that HCA can present an indirect inhibitory effect toward the acceleration of FXa to t-PA-catalyzed plasminogen activation, but does not interact with t-PA directly.

\section{In vivo study}

\section{Mouse tail-bleeding experiment}

As shown in Table 1, compared with the control group, HCA $(0.25,0.125,0.0625 \mu \mathrm{g} / \mathrm{kg})$ and reptilase markedly shortened the bleeding time in the hemorrhagic area after $30 \mathrm{~min}$ $(p<0.05)$. The bleeding time of mice treated with HCA $(0.25 \mu \mathrm{g} / \mathrm{kg})$ or reptilase showed no significant difference.

\section{Effects of HCA on the fibrinogen levels in rabbits}

As shown in Table 2, HCA can hardly influence the blood levels of fibrinogen in rabbits. Compared to the pre-administration data, no difference in the blood fibrinogen concentration was found in the rabbits administered with $\mathrm{HCA}$ (HCA 0.25 and $0.125 \mu \mathrm{g} / \mathrm{kg})(p>0.05)$ postadministration. However, the content of fibrinogen in the batroxobin group was significantly decreased after 0.5 and $2 \mathrm{~h}(p<0.01)$, which is in agreement with previously published findings. ${ }^{33}$ These results indicate that HCA might not activate the fibrinolytic system even after the formation of fibrin monomers in the plasma and thus lead to reduction of the content of fibrin (fibrinogen) in vivo. 
A

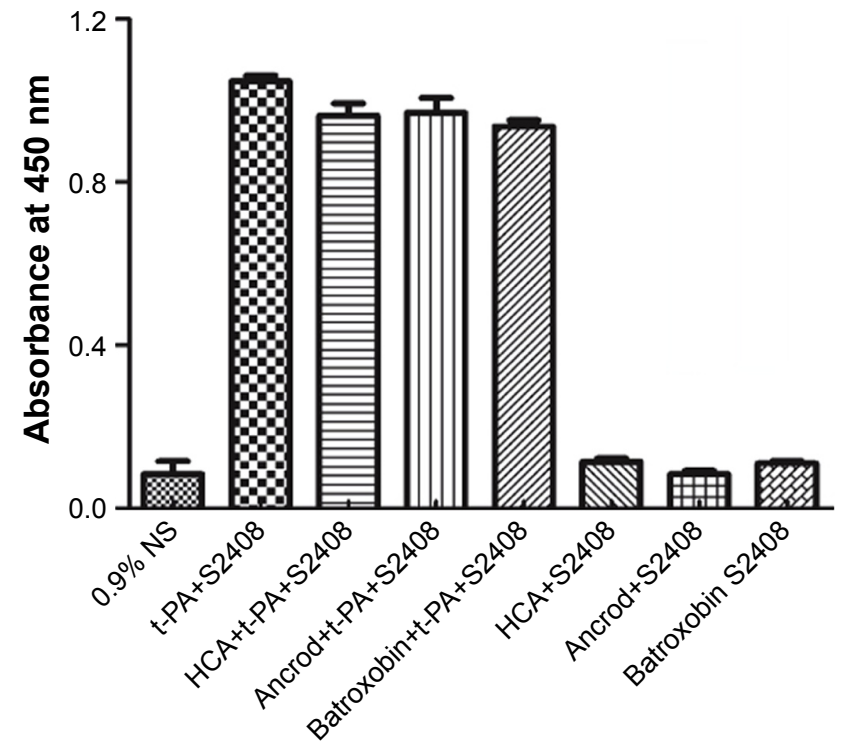

B

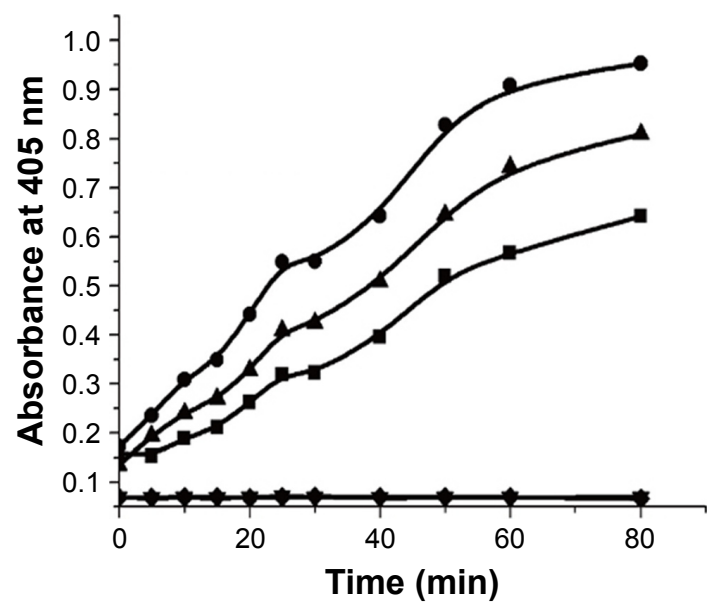

- PCPS+Lys-Pg+ $\quad$ A PCPS+Lys-Pg+

FXa+t-PA

- PCPS+Lys-Pg+t-PA v HCA+S2408

- Ancrod+S2408

Figure 5 (A) Effect of HCA to the activation of t-PA; (B) The indirect inhibitory effects of HCA and ancrod on the acceleration of FXa to t-PA-catalyzed plasminogen activation. S2403 is a kind of chromogenic substrate. The values shown are the mean \pm SEM $(n=3)$.

Abbreviations: FXa, active factor X; HCA, hemocoagulase agkistrodon; Lys-Pg, Lys-plasminogen; NS, normal saline; PCPS, small unilamellar phospholipid vesicles; t-PA, tissue plasminogen activator.

\section{Discussion}

TLEs are enzymes that are functionally related to thrombin. These enzymes belong to a class of serine proteases that can hydrolyze fibrinogen into fibrin, presenting in vitro coagulation and in vivo defibrin(ogen)ation activities. ${ }^{34-37}$ TLEs have been widely investigated because of their ability to prevent and stop surgical bleeding as well as to treat ischemic cerebral infarction. ${ }^{38-40}$ Tang et al have isolated and characterized five new TLEs from $A$. acutus snake venom from 1993 to $2005 .{ }^{11}$ HCA is also a type of TLEs purified from A. acutus snake venom, which has good hemostatic effects.

Our current study has shown that HCA could release fibrous protein peptides (data shown in Figure S1); the release of FPBs was observed $2 \mathrm{~h}$ after the treatment of HCA, so we assume that this characteristic could strengthen

Table I Effects of HCA on the bleeding time in mouse tailbleeding model $(\bar{x} \pm$ SEM, $\mathrm{n}=10)$

\begin{tabular}{lll}
\hline Group & $\mathbf{N}$ & Bleeding time (s) \\
\hline Vehicle & 10 & $153.5 \pm 32.1$ \\
HCA $0.25 \mu \mathrm{g} / \mathrm{kg}$ & 10 & $71.7 \pm 21.2^{*}$ \\
$\mathrm{HCA} 0.125 \mu \mathrm{g} / \mathrm{kg}$ & 10 & $108.8 \pm 30.9^{*, \#}$ \\
$\mathrm{HCA} 0.0625 \mu \mathrm{g} / \mathrm{kg}$ & 10 & $109.1 \pm 36.3^{*, \#}$ \\
Reptilase $0.5 \mathrm{kU} / \mathrm{kg}$ & 10 & $87.9 \pm 14.8^{*}$
\end{tabular}

Notes: *Compared with vehicle, $p<0.05$; ${ }^{*}$ compared with HCA $0.25 \mu \mathrm{g} / \mathrm{kg}, p<0.05$. Abbreviations: HCA, hemocoagulase agkistrodon; SEM, standard error of mean. its hemostatic activity because of the role of FPBs in the aggregation of the primary fibers. The formed fibrin monomers produced by HCA in the hemostasis process may form a covalent cross-linkage within the $\gamma$-chains (data shown in Figure S2), which might be engulfed by the reticuloendothelial system and eliminated by the circulating system, thus being dissolved easier. However, HCA was unable to promote the activation of FXIII (data shown in Figure S3), which is similar to other TLEs. ${ }^{23,41}$ Moreover, HCA was unable to promote the activation of FX, FII and plasminogen (data shown in Figure S4), thus the activation of the coagulation pathway and the fibrinolysis system could not occur, eliminating the risk of thrombus formation and hyponatremia in the body and avoiding risks associated with the injection dosage. After further studying the in vitro influence of HCA on the coagulation system, we also found that HCA did not show any activity at $\mathrm{pH} 4.5$, and was unable to achieve plasma coagulation. As the $\mathrm{pH}$ increased, HCA showed the highest activity in a partially acidic buffer solution at $\mathrm{pH}$ 5.5, but poor activity in alkaline solution (Figure 1A). Furthermore, the optimum temperature for HCA activity was $35^{\circ} \mathrm{C}$. Besides, with a continuous increase in the $\mathrm{Ca}^{2+}$ concentration, the fibrinogen clotting time was continuously shortened, and the presence of $\mathrm{Ca}^{2+}$ could contribute to the coagulation of fibrinogen. In addition, as expected, 
Table 2 Effects of HCA on the rabbit blood fibrinogen $(\bar{x} \pm$ SEM, $\mathrm{n}=6)$

\begin{tabular}{|c|c|c|c|c|c|c|}
\hline \multirow[t]{2}{*}{ Group } & \multirow[t]{2}{*}{$\begin{array}{l}\text { Before } \\
\text { administration (iv) }\end{array}$} & \multicolumn{5}{|c|}{$\begin{array}{l}\text { Blood fibrinogen concentration }(\mathrm{mg} / \mathrm{dL}) \text { after administration (iv) at various } \\
\text { time points }\end{array}$} \\
\hline & & $0.5 \mathrm{~h}$ & I h & $2 \mathrm{~h}$ & $4 \mathrm{~h}$ & $6 \mathrm{~h}$ \\
\hline Vehicle & $638.1 \pm 65.1$ & $625.3 \pm 65.3$ & $611.8 \pm 66.3$ & $609.7 \pm 67.8$ & $631.0 \pm 52.6$ & $653.0 \pm 57.4$ \\
\hline $\mathrm{HCA} 0.25 \mu \mathrm{g} / \mathrm{kg}$ & $468.7 \pm 71.4$ & $483.7 \pm 64.3$ & $473.7 \pm 66.4$ & $475.1 \pm 65.0$ & $484.6 \pm 73.8$ & $476.5 \pm 71.9$ \\
\hline HCA $0.125 \mu g / k g$ & $498.7 \pm 74.5$ & $509.6 \pm 67.0$ & $497.0 \pm 76.0$ & $459.8 \pm 70.9$ & $507.9 \pm 69.0$ & $521.3 \pm 68.0$ \\
\hline Batroxobin $0.5 \mathrm{BU} / \mathrm{kg}$ & $526.0 \pm 38.9$ & $483.5 \pm 42.7 * *$ & $486.2 \pm 55.7^{* *}$ & $484.3 \pm 47.7^{* *}$ & $507.7 \pm 51.9$ & $522.3 \pm 49.5$ \\
\hline
\end{tabular}

Note: ${ }^{* *} p<0.0$ I by paired-samples $t$-test vs vehicle.

Abbreviations: HCA, hemocoagulase agkistrodon; SEM, standard error of mean; iv, intravenous.

PMSF could inhibit the coagulation activity of HCA in a dose-dependent manner (Figure 1D), but heparin and EDTA did not, which is similar to reptilase, indicating that HCA is likely a serine protein-like venom thrombin. Many reports have shown that $\mathrm{Ca}^{2+}$ plays a certain role in preventing the thermal denaturation of fibrinogen, accelerating the whole blood coagulation reaction, and protecting disulfide bonds from breaking or inhibiting the plasmin to cleave some special peptide bonds. ${ }^{42,43}$ It is also believed that the uptake of $\mathrm{Ca}^{2+}$ is related to the release of fibrinopeptides, and the release of FPB is often accompanied by $\mathrm{Ca}^{2+}$ uptake; the speed of the FPA release was four times faster than the uptake process. The release of FPA is related to the accumulation of fibrin and the formation of fibrin clots. However, ancrod, a type of TLEs which can only release FPA, could interact with $\mathrm{Ca}^{2+}$ at lower concentrations, indicating that the $\mathrm{Ca}^{2+}$ binding site of fibrin is likely located near to the FPB release sites. With the concentration increased, the clotting time mediated by HCA was constantly shortened. Above all, it can be concluded that $\mathrm{Ca}^{2+}$ can strengthen the activity of HCA, as HCA was able to release the FPB in the presence of $\mathrm{Ca}^{2+}$. According to the results from the simulated coagulation environment by using standard human plasma, we speculate that the formed fibrin monomers mediated by HCA in the hemostasis process may form a covalent crosslinkage within the $\gamma$-chains in the absence or presence of $\mathrm{Ca}^{2+}$ (Figure 2A and B), thus making it easier for the clot to be dissolved. In addition, the clot formed by HCA from heparinized human plasma was strikingly more vulnerable to $5 \mathrm{M}$ urea solution than the clot formed by reptilase (data not shown). The reason is unclear, but the results indicated that the fibrin clots produced by HCA probably have a different structure compared with those produced by other TLEs. ${ }^{44,45}$ In addition, HCA could obviously inhibit the action of the FII complexes in a dose-dependent manner by significantly reducing its activation degree and speed. The activation of FII complexes by FII was almost completely inhibited when the concentration of HCA reached $300 \mathrm{nM}$ (Figure 4). The results from studying the impact of HCA on the anticoagulation system showed that HCA had a strong binding capacity with the FX/FXa/FIX/FIXa complex in a ratio of $1: 1$, and their binding capacity magnitude was in the order of: $\mathrm{FXa}>\mathrm{FX}>$ FIXa $>$ FIX (Figure $3 \mathrm{~B}$ and $\mathrm{C}$ ). In addition, HCA could not activate the profibrinolysin into fibrinolytic enzyme directly, but could suppress the activation effect of $\mathrm{t}-\mathrm{PA}$ on the activation of profibrinolysin by binding to $\mathrm{FXa}$ (Figure 5B). In summary, HCA can form complexes with coagulation factors, thus inhibiting the partial anticoagulant effects of $\mathrm{FX} / \mathrm{FXa} / \mathrm{FIX} / \mathrm{FIXa} .{ }^{46}$ Additionally, HCA binding to blood coagulation factors, within the range of effective hemostatic concentrations, can inhibit the potent fibrinogenclotting action of HCA in vivo. Collectively, we speculate that these unique biological functions of HCA, and possibly other unknown biological properties, may contribute to the hemostatic effect of HCA in the hemorrhagic area. However, further research is required to illuminate the hemostatic mechanisms of HCA in vivo and promote its therapeutic use in clinical practice. The results obtained in this study suggest that HCA could be potentially a safer hemostatic drug for preventing thrombus formation due to its interactions with the coagulation factors. It has been reported that the inhibition of FXa can prevent thrombosis and blood coagulation. ${ }^{47-49}$ In this study, we have demonstrated for the first time that HCA could bind to FXa, which supports the potential therapeutic role of HCA in clinical practice as a hemostatic drug for preventing thrombosis.

Meanwhile, we have also investigated the effect of HCA in vivo to further demonstrate its role in hemostasis. Data from the mouse tail-bleeding assay showed that HCA could significantly shorten the bleeding time (Table 1). Moreover, results from the New Zealand rabbits showed that HCA did not reduce the normal plasma fibrinogen levels even when administered at the highest clinical dosage (Table 2). However, a significant decrease could be observed after the application of batroxobin (a type of defibrinogenase like ancrod, which inhibits thrombus formation through FPA 
release and fibrinolysis system activation) for $0.5 \mathrm{~h}$, indicating that the fibrin fragments hydrolyzed by HCA probably do not activate the fibrinolytic system.

\section{Conclusion}

In summary, we have demonstrated that HCA, as a new family member of TLEs, interacts with the blood coagulation system in a distinctive and complex manner, which might be beneficial for its application as a potent clinical drug for the prevention and treatment of hemorrhagic diseases. ${ }^{50}$ Our findings are contradictory to the general concept that the TLEs possess only enzymatic activity, and provide a new insight into the understanding of the structure and function of TLEs. ${ }^{11,51-53}$ However, more research is required to clarify these features, which will enable us to further understand the mechanism of action of HCA and promote its usage as a potent hemostatic drug.

\section{Acknowledgments}

We acknowledge Dr Jiansheng Huang (Northwestern University, USA) and Professor Shuwen Liu (Southern Medical University, People's Republic of China) for their thoughtful review of the manuscript. This work was supported by grants from the National Natural Science Foundation of China (81273577/H3109). Haixin Li and Ying Huang should be considered co-first authors.

\section{Author contributions}

Jianxin Pang and Qun Zhang conceived and designed the experiments; Haixin Li, Ying Huang, Xian Wu, Ting Wu, Qimei Wang, and Yuchang Qiu performed the experiments; Ying Cao and Ting $\mathrm{Wu}$ analyzed the data; Ting $\mathrm{Wu}$ and Haixin Li contributed reagents/materials/analysis tools; Ting $\mathrm{Wu}$ wrote the paper. All authors contributed toward data analysis, drafting and critically revising the paper and agree to be accountable for all aspects of the work.

\section{Disclosure}

The authors report no conflicts of interest in this work.

\section{References}

1. Esmon CT. Regulation of blood coagulation. Biochim Biophys Acta. 2000;1477:349-360.

2. Goto S, Tomita A. Antithrombotic therapy for prevention of various thrombotic diseases. Drug Dev Res. 2013;74:568-574.

3. Hurwitt ES, Henderson J, Lord GH, Gitlitz GF, Lebendiger A. A new surgical absorbable hemostatic agent: experimental and clinical evaluation. Am J Surg. 1960;100:439-446.

4. Stubbs MT, Bode W. Coagulation factors and their inhibitors. Curr Opin Struc Biol. 1994;4:823-832.
5. Monroe DM, Hoffman M. The coagulation cascade in cirrhosis. Clin Liver Dis. 2009;13:1-9.

6. Marsh N, Williams V. Practical applications of snake venom toxins in haemostasis. Toxicon. 2005;45:1171-1181.

7. Matsui T, Fujimura Y, Titani K. Snake venom proteases affecting hemostasis and thrombosis. Biochim Biophys Acta. 2000;1477:146-156.

8. Braud S, Bon C, Wisner A. Snake venom proteins acting on hemostasis. Biochimie. 2000;82:851-859.

9. Vivas-Ruiz DE, Sandoval GA, Mendoza J, et al. Coagulant thrombinlike enzyme (barnettobin) from Bothrops barnetti venom: molecular sequence analysis of its cDNA and biochemical properties. Biochimie. 2013;95:1476-1486.

10. Mukherjee AK, Mackessy SP. Biochemical and pharmacological properties of a new thrombin-like serine protease (Russelobin) from the venom of Russell's viper (Daboia russelii russelii) and assessment of its therapeutic potential. Biochim Biophys Acta. 2013;1830:3476-3488.

11. Tang SS, Wang XH, Zhang JH, et al. Biochemical properties and comparative pharmacology of a coagulant from Deinagkistrodon acutus snake venom. Eur J Pharm Sci. 2013;49:90-98.

12. Zheng Y, Ye FP, Wang J, et al. Purification, characterization and gene cloning of Da-36, a novel serine protease from Deinagkistrodon acutus venom. Toxicon. 2013;67:1-11.

13. Davie EW, Fujikawa K, Kurachi K, Kisiel W. The role of serine proteases in the blood coagulation cascade. Adv Enzymol Relat Areas Mol Biol. 1979;48:277-318.

14. Vilca-Quispe A, Ponce-Soto LA, Winck FV, Marangoni S. MarangoniIsolation and characterization of a new serine protease with thrombin-like activity (TLBm) from the venom of the snake Bothrops marajoensis. Toxicon. 2010;55:745-753.

15. Ouyang $C$. The effects of Formosan snake venoms on blood coagulation in vitro. J Formosan Med Ass. 1957;56:435.

16. Pirkle H. Thrombin-like enzymes in snake venoms: an updated inventory. Scientific and Standardization Committee's Registry of Exogenous Hemostatic Factors. Thromb Haemostasis. 1998;79:675-683.

17. Blomback B, Blomback M, Nilsson IM. Coagulation studies on reptilase, an extract of the venom from Bothrops jararaca. Thromb Diath Haemorrh. 1958;1:76-86.

18. Castro HC, Zingali RB, Albuquerque MG, Pujol-Luz M, Rodrigues CR. Snake venom thrombin-like enzymes: from reptilase to now. Cell Mol Life Sci. 2004;61:843-856.

19. Markland FS. Snake venoms and the hemostatic system. Toxicon. 1998;36:1749-1800.

20. Wang QC, Liu GF. A new antithrombotic agent acutobin. Chinese New Drugs Journal. 2000;9:270-272. Chinese.

21. Huang QQ, Teng MK, Niu LW. Purification and characterization of two fibrinogen-clotting enzymes from five-pace snake (Agkistrodonacutus) venom. Toxicon. 1999;37:999-1013.

22. Pan H, Du X, Yang G, Zhou Y, Wu X. cDNA cloning and expression of acutin, a thrombin-like enzyme from Agkistrodonacutus. Biochem Bioph Res Co. 1999;255:412-415.

23. Liu SJ, Huang QQ, Zhu XY, Teng MK, Niu LW. Purification, characterization, crystallization and preliminary X-ray diffraction of acuthrombin-B, a thrombin-like enzyme from Agkistrodonacutus venom. Acta Crystallogr D Biol Crystallogr. 1999;55:1193-1197.

24. Wei JM, Zhu MW, Zhang ZT, et al. A multicenter, phase III trial of hemocoagulase Agkistrodon: hemostasis, coagulation, and safety in patients undergoing abdominal surgery. Chin Med J. 2010;123:589-593.

25. Zhou JJ, Huang ZH, Yu JL, Li Z, Zhou GJ. Phase IIa clinical trial of hemocoagulase acutus for injection. Nan Fang Yi Ke Da Xue Xue Bao. 2007;27:644-646.

26. Atoda H, Yoshida N, Ishikawa M, Morita T. Binding properties of the coagulation factor IX/factor X-binding protein isolated from the venom of Trimeresurus flavoviridis. Eur J Biochem. 1994;224:703-708.

27. Higgins DL, Mann KG. The interaction of bovine factor $\mathrm{V}$ and factor V-derived peptides with phospholipid vesicles. J Biol Chem. 1983; 258:6503-6508. 
28. Cui L, Dong MS, Chen XH, Jiang M, Lv X. A novel fibrinolytic enzyme from Cordyceps militaris, a Chinese traditional medicinal mushroom. World J Microb Biot. 2008;24:483-489.

29. Jiang W, Ma T, Su X, Qiu P, Yan G. Enzymatic activities and functional characterization of a novel recombinant snake venom proteinase from Agkistrodon acutus. Biochimie. 2009;91:277-287.

30. Koklic T, Chattopadhyay R, Majumder R, Lentz BR. Factor Xa dimerization competes with prothrombinase complex formation on platelet-like membrane surfaces. Biochem J. 2015;467:37-46.

31. Talbot K, Meixner SC, Pryzdial EL. Enhanced fibrinolysis by proteolysed coagulation factor Xa. Biochim Biophys Acta. 2010;1804:723-730.

32. Mukherjee AK, Mackessy SP. Biochemical and pharmacological properties of a new thrombin-like serine protease (Russelobin) from the venom of Russell's viper (Daboia russelii russelii) and assessment of its therapeutic potential. Biochim Biophys Acta. 2013;1830:3476-3488.

33. Inoue A, Koh CS, Shimada K, Yanagisawa N, Yoshimura K. Suppression of cell-transferred experimental autoimmune encephalomyelitis in defibrinated Lewis rats. J Neuroimmunol. 1996;71:131-137.

34. Vander Dos Santos R, Villalta-Romero F, Stanisic D, Borro L, Neshich G, Tasic L. Citrus bioflavonoid, hesperetin, as inhibitor of two thrombin-like snake venom serine proteases isolated from Crotalus simus. Toxicon. 2018;143:36-43.

35. Hutton RA, Warrell DA. Action of snake venom components on the haemostatic system. Blood Rev. 1993;7:176-189.

36. Li S, Ji H, Cheng X, Li BX, Ng TB. Antithrombotic and thrombolytic activities of Agkisacutacin, a snake venom proteinase, in experimental models. Gen Pharmacol. 2000;35:179-187.

37. Zhu Z, Gong W, Zhu X, Teng M, Niu L. Purification, characterization and conformational analysis of a haemorrhagin from the venom of Agkistrodon acutus. Toxicon. 1997;35:283-292.

38. Castro HC, Zingali RB, Albuquerque MG, Pujol-Luz M, Rodrigues CR. Snake venom thrombin-like enzymes: from reptilase to now. Cell Mol Life Sci. 2004;61:843-856.

39. Swenson S, Markland FS Jr. Snake venom fibrin(ogen)olytic enzymes. Toxicon. 2005;45:1021-1039.

40. Vu TT, Stafford AR, Leslie BA, Kim PY, Fredenburgh JC, Weitz JI. Weitz Batroxobin binds fibrin with higher affinity and promotes clot expansion to a greater extent than thrombin. J Biol Chem. 2013;288: 16862-16871.

41. Palatty PL, Saldanha E. The medicinal use of venoms and toxins. J Indian Med Assoc. 2013;111:51-53.
42. Mihalyi E. Review of some unusual effects of calcium binding to fibrinogen. Biophys Chem. 2004;112:131-140.

43. Carr ME Jr, Gabriel DA, McDonagh J. Influence of $\mathrm{Ca} 2+$ on the structure of reptilase-derived and thrombin-derived fibrin gels. Biochem J. 1986;239:513-516.

44. Okumura N, Terasawa F, Haneishi A, et al. B:b interactions are essential for polymerization of variant fibrinogens with impaired holes "a". J Thromb Haemost. 2007;5:2352-2359.

45. Weisel JW, Veklich Y, Gorkun O. The sequence of cleavage of fibrinopeptides from fibrinogen is important for protofibril formation and enhancement of lateral aggregation in fibrin clots. J Mol Biol. 1993;232: 285-297.

46. Zhang Y, Xu X, Shen D, Song J, Guo M, Yan X. Anticoagulation factor I, a snaclec (snake C-type lectin) from Agkistrodon acutus venom binds to FIX as well as FX: Ca2+ induced binding data. Toxicon. 2012; 59:718-723.

47. Xia S, Li J, Zu M, et al. Small size fullerenol nanoparticles inhibit thrombosis and blood coagulation through inhibiting activities of thrombin and FXa. Nanomedicine. 2018;14(3):929-939.

48. Jiang L, Wang Q, Shen S, Xiao T, Li Y. Discovery of glycyrrhetinic acid as an orally active, direct inhibitor of blood coagulation factor xa. Thromb Res. 2014;133:501-506.

49. Konishi N, Hiroe K, Kawamura M. Differential effects of TAK-442, a novel orally active direct factor $\mathrm{Xa}$ inhibitor, and ximelagatran, a thrombin inhibitor, on factor V-mediated feedback on coagulation cascade and bleeding. Thromb Haemostasis. 2010;104:504-513.

50. Mukherjee AK, Mackessy SP. Biochemical and pharmacological properties of a new thrombin-like serine protease (Russelobin) from the venom of Russell's viper (Daboia russelii russelii) and assessment of its therapeutic potential. Biochim Biophys Acta. 2013;1830:3476-3488.

51. Pradniwat $P$, Rojnuckarin $P$. The structure-function relationship of thrombin-like enzymes from the green pit viper (Trimeresurus albolabris). Toxicon. 2015;100:53-59.

52. Menaldo DL, Bernardes CP, Santos-Filho NA, et al. Biochemical characterization and comparative analysis of two distinct serine proteases from Bothrops pirajai snake venom. Biochimie. 2012;94:2545-2558.

53. Valeriano-Zapana JA, Segovia-Cruz FS, Rojas-Hualpa JM, Martinsde-Souza D, Ponce-Soto LA, Marangoni S. Functional and structural characterization of a new serine protease with thrombin-like activity TLBan from Bothrops andianus (Andean Lancehead) snake venom. Toxicon. 2012;59:231-240. 


\section{Supplementary materials}

\section{The preparation of polyclonal antibody}

Two milliliters of auricular vein blood was obtained from male New Zealand rabbits weighing around $2 \mathrm{~kg}$ before immunization. The serum was prepared as negative control and stored at $-20^{\circ} \mathrm{C}$. For the primary immunization, $1 \mathrm{mg}$ of hemocoagulase agkistrodon (HCA) was dissolved in $3 \mathrm{~mL}$ of physiological saline and mixed (1:1) with complete Freund's adjuvant. The subcutaneous injections were made in different regions of animals' back and scapular region in addition to one intramuscular injection. For subsequent booster immunization, $0.5 \mathrm{mg}$ of HCA was dissolved in $3 \mathrm{~mL}$ of physiological saline mixed (1:1) with incomplete Freund's adjuvant and injected at 4th, 6th, 8th, and 10th weeks. After 5-7 days of the primary and booster immunizations, $2 \mathrm{~mL}$ of rabbit auricular vein blood was collected, and the serum was separated. Double immune-diffusion was performed to test the antibody titer of the serum. Ten days after the last immunization, $100 \mathrm{~mL}$ of whole blood was drawn from the carotid artery and stored in refrigerator at $4^{\circ} \mathrm{C}$ for $4 \mathrm{~h}$ after clotting at room temperature, and then the serum was separated and frozen at $-20^{\circ} \mathrm{C}$.

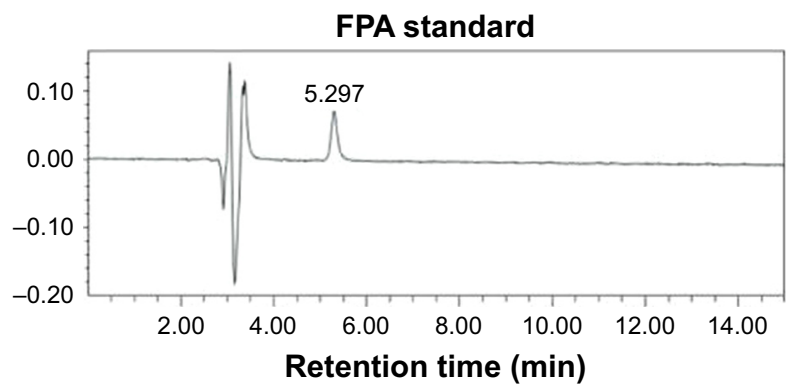

Thrombin+Fib (30 $\mathrm{min})$

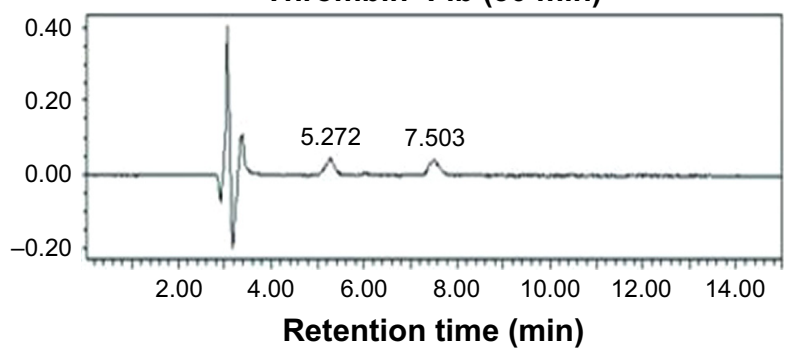

Figure SI (Continued)

\section{The preparation of PCPS}

L- $\alpha$-phosphatidylcholine $7.5 \mathrm{mg}$ and L- $\alpha$-phosphatidylserine $2.5 \mathrm{mg}$ were accurately weighted and placed into a $4 \mathrm{~mL}$ Eppendorf (EP) tube, which was dried by using nitrogen. Then $4 \mathrm{~mL}$ HEPES buffer (0.02 M HEPES, $0.15 \mathrm{M} \mathrm{NaCl}$, $\mathrm{pH}$ 7.4) was added and the mixture was vortexed evenly. The above solution was dispensed into two $4 \mathrm{~mL}$ EP tubes. The EP tubes equipped with small unilamellar phospholipid vesicles (PCPS) were placed into an ice bath. Under the condition of nitrogen flow, the PCPS suspension was sonicated with a probe-type ultrasound with an ultrasonic power of $100 \mathrm{~W}$ and an ultrasonic time of $30 \mathrm{~min}$ (until the solutions turned to be transparent). The vesicle suspension was centrifuged at 35,000 rpm for $30 \mathrm{~min}$ at $4^{\circ} \mathrm{C}$; again, the suspension was centrifuged at $40,000 \mathrm{rpm}$ for $3 \mathrm{~h}$ at $4^{\circ} \mathrm{C}$. Then the suspension was divided into three layers. The clear supernatant is the uniform single-layer vesicle we are interested in. Then, the concentration of the phospholipid in the phospholipid vesicles was detected, and nitrogen gas was allowed to flow into the tube containing the uniform monolayers of phospholipid vesicles. The obtained samples were stored at $4{ }^{\circ} \mathrm{C}$ and were used within $24 \mathrm{~h}$.

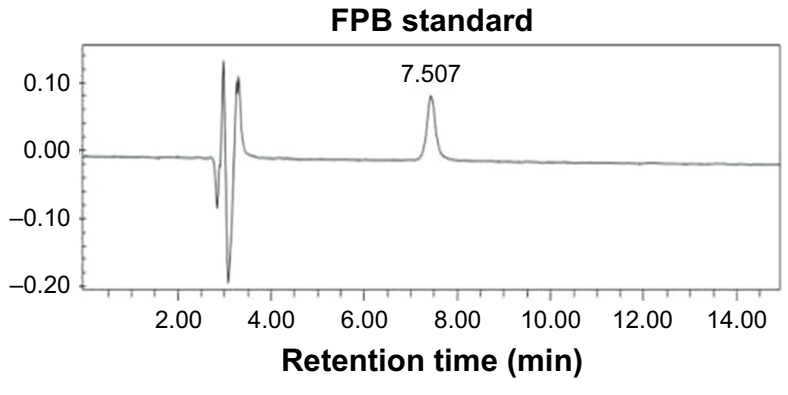

HCA+Fib (10 min)

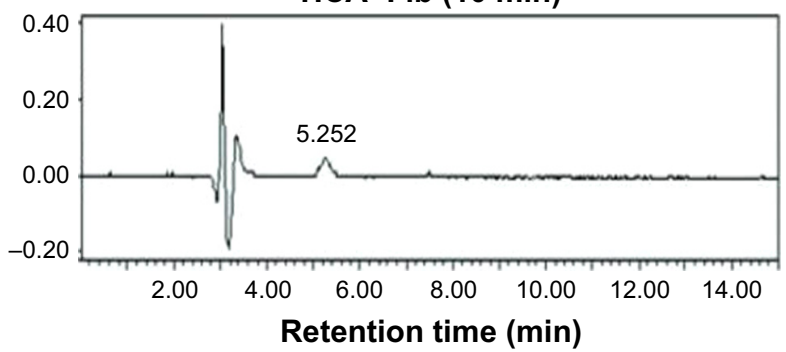



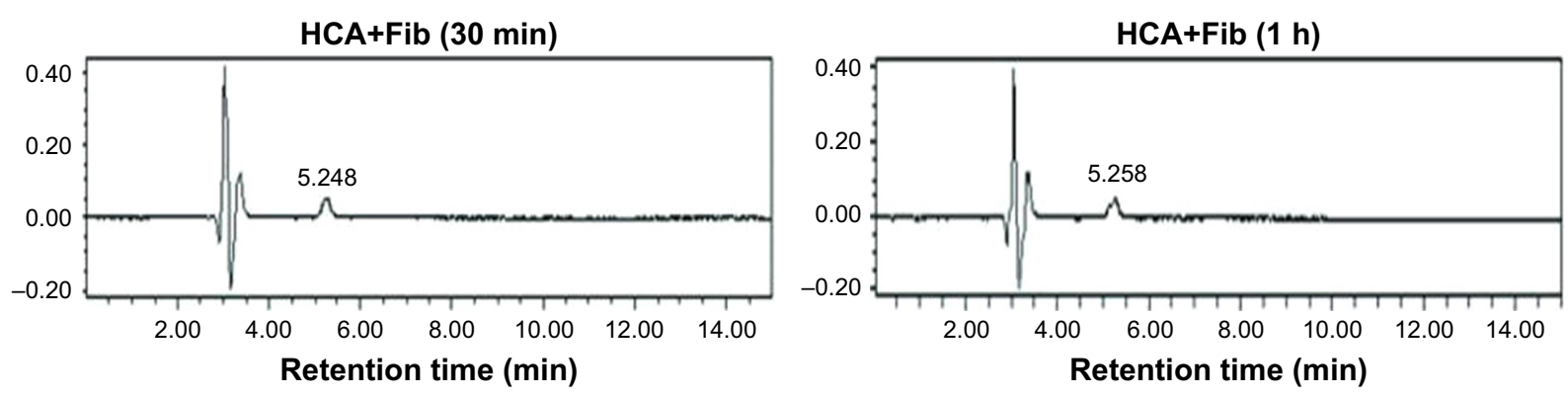

HCA+Fib (2 h)
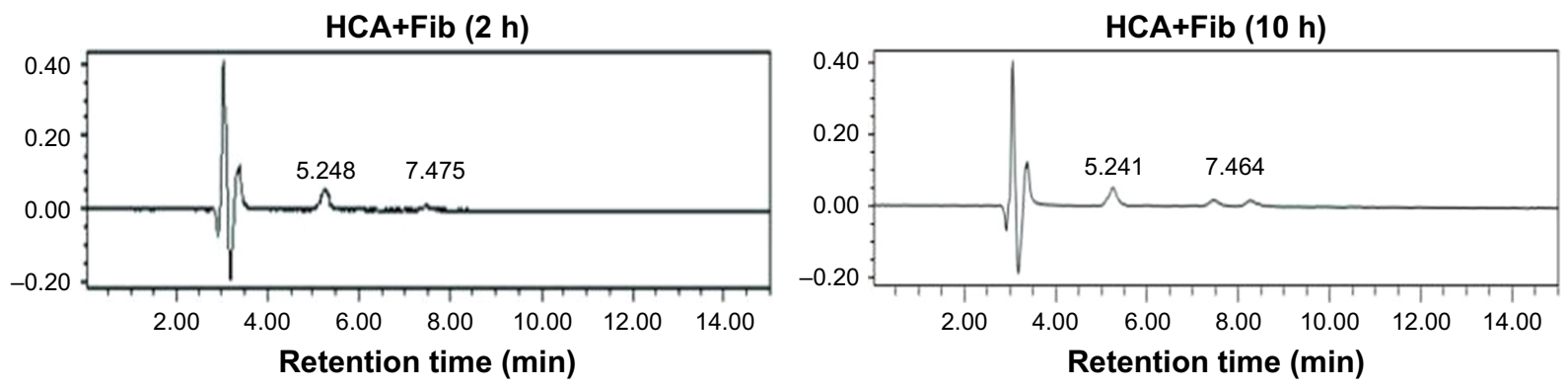

Figure $\mathbf{S I}$ Analysis of fibrinopeptides using reverse-phase HPLC.

Abbreviations: HCA, hemocoagulase agkistrodon; FPA, fibrinopeptide A; FPB, fibrinopeptide B; Fib, fibrinogen; HPLC, high-pressure liquid chromatography.
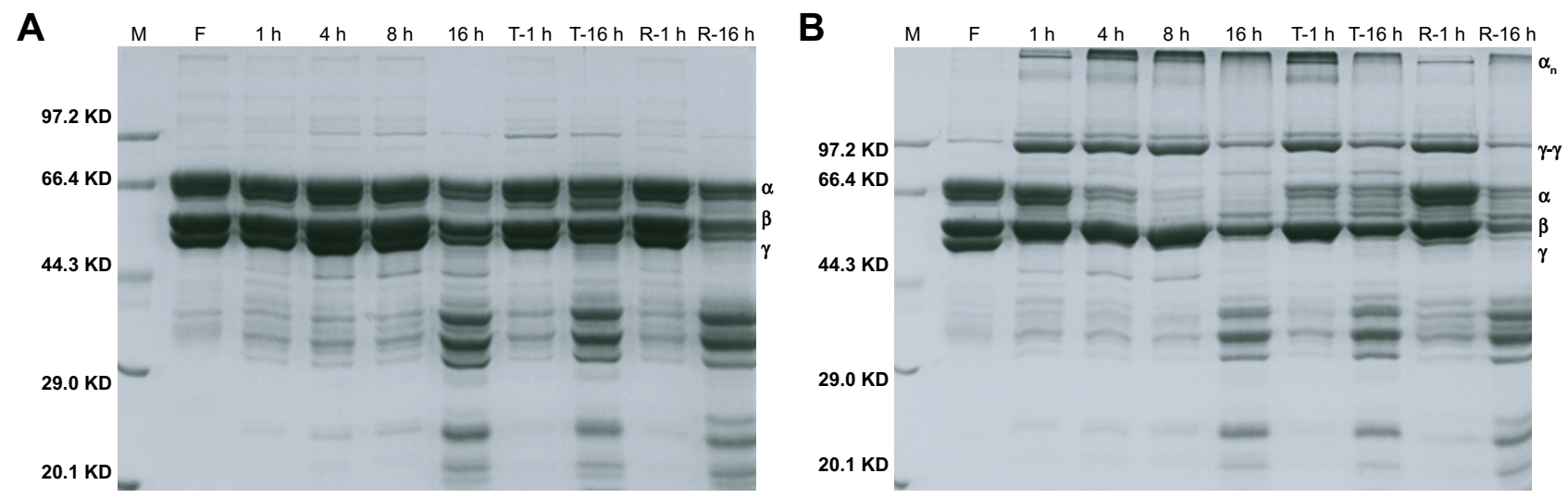

Figure S2 Hydrolysis of HCA to fibrinogen with time-course analysis by SDS-PAGE in the absence (A) or presence (B) of Ca ${ }^{2+}$ ( $10 \%$ acrylamide gels). Lane M: PMW markers; Lane F: fibrinogen solution for 16 h; Lane I-16 h: fibrinogen hydrolyzed by HCA for I, 4, 8, and I6 h; Lane T-I h and T- 16 h: fibrinogen hydrolyzed by thrombin for I h and $16 \mathrm{~h}$, respectively; Lane R-I h and R-16 h: fibrinogen hydrolyzed by reptilase for I h and $16 \mathrm{~h}$, respectively. $\alpha, \beta$, and $\gamma$ stand for the three subunit bands of fibrinogen. Molecular masses of the markers are shown on the left.

Abbreviations: HCA, hemocoagulase agkistrodon; SDS-PAGE, sodium dodecyl sulfate polyacrylamide gel electrophoresis; PMW, molecular weight of standard protein.

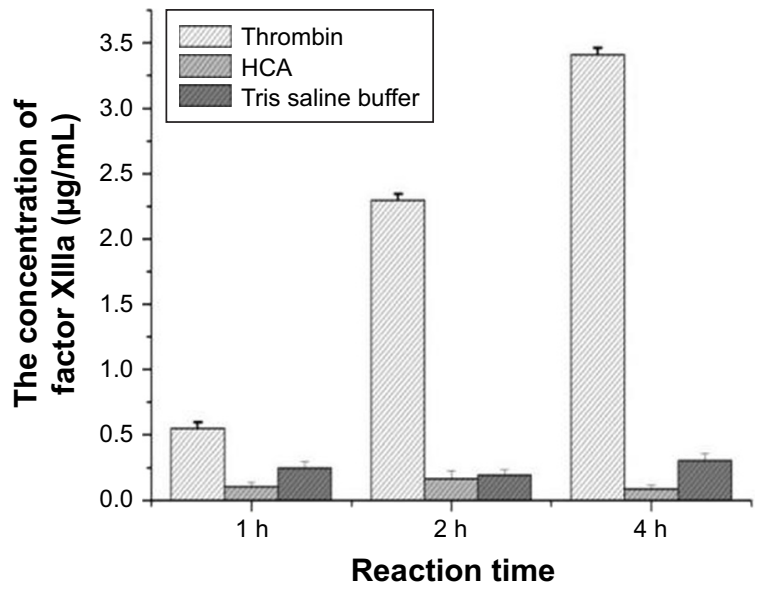

Figure S3 Effects of HCA and thrombin on the activation activity of human factor XIII. Abbreviation: HCA, hemocoagulase agkistrodon. 


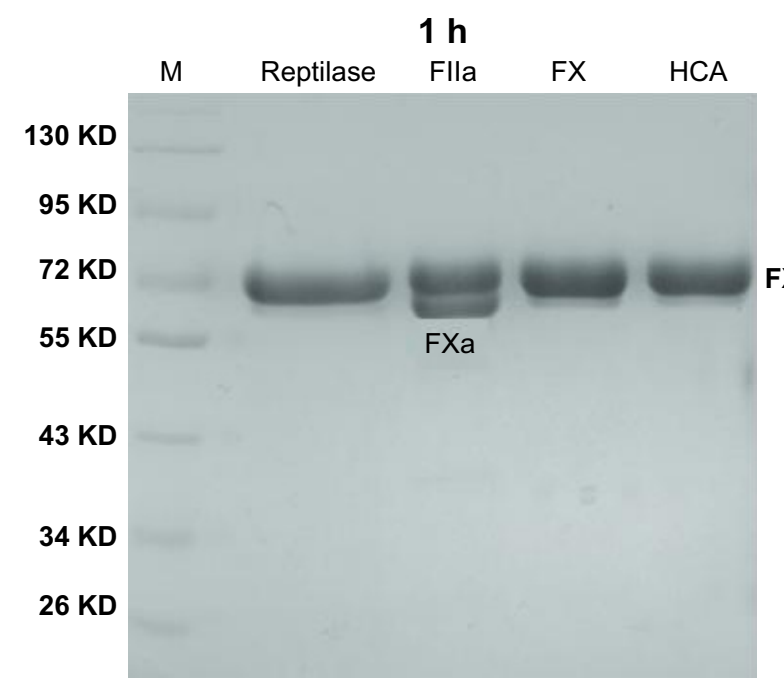

$4 \mathrm{~h}$

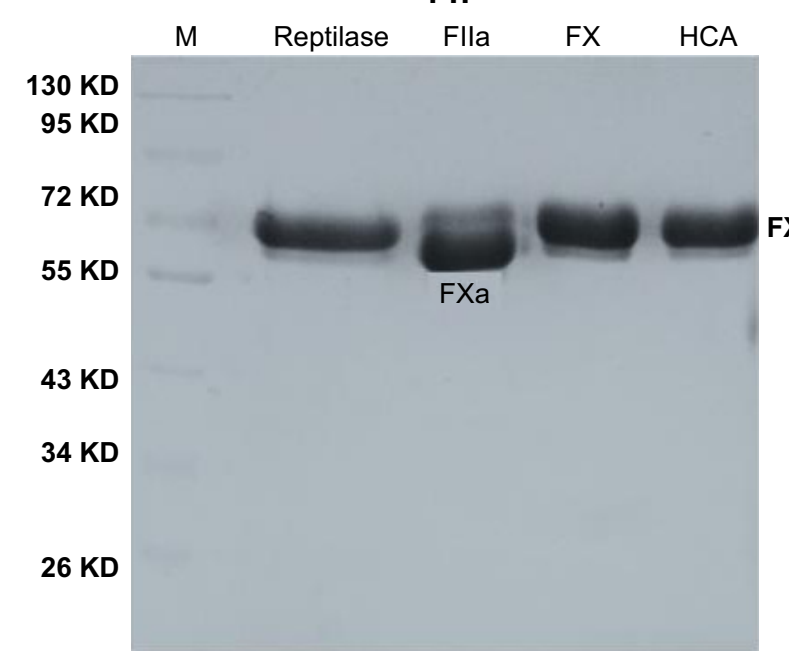

$2 \mathrm{~h}$

Flla FX HCA

$130 \mathrm{KD}$

M Reptilase

M Reptilase Flla

FX

$95 \mathrm{KD}$

$\mathrm{X} \quad \mathbf{K D}$

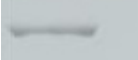

$55 \mathrm{KD}$

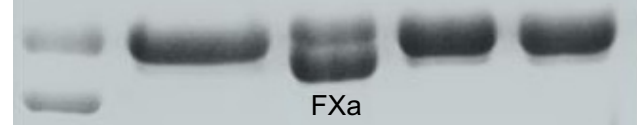

FX

$43 \mathrm{KD}$

34 KD

$26 \mathrm{KD}$

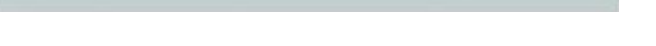

$8 \mathrm{~h}$

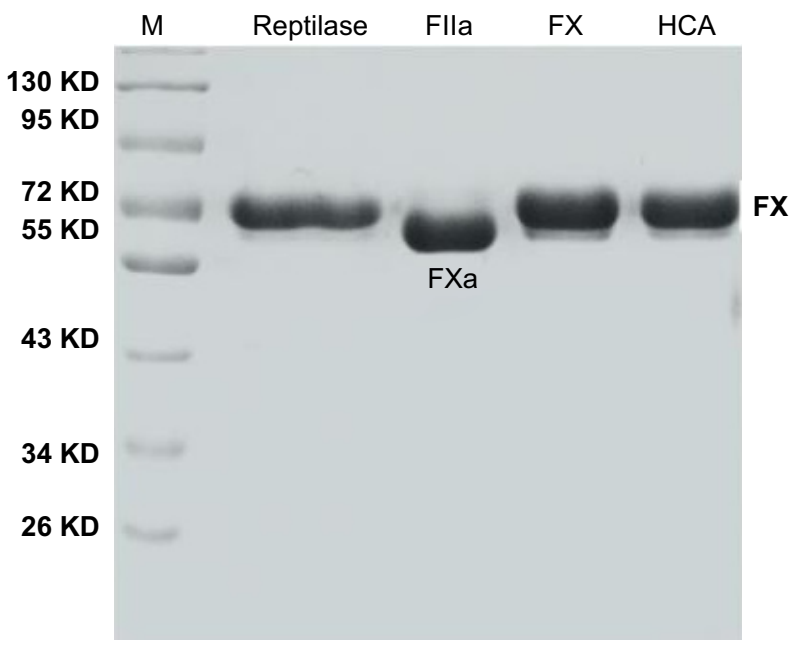

Figure S4 Effects of HCA and reptilase on the hydrolysis of FX.

Abbreviations: HCA, hemocoagulase agkistrodon; Flla, thrombin; FX, coagulation factor X; M, marker.

Drug Design, Development and Therapy

\section{Publish your work in this journal}

Drug Design, Development and Therapy is an international, peerreviewed open-access journal that spans the spectrum of drug design and development through to clinical applications. Clinical outcomes, patient safety, and programs for the development and effective, safe, and sustained use of medicines are the features of the journal, which

\section{Dovepress}

has also been accepted for indexing on PubMed Central. The manuscript management system is completely online and includes a very quick and fair peer-review system, which is all easy to use. Visit http://www.dovepress.com/testimonials.php to read real quotes from published authors.

Submit your manuscript here: http://www.dovepress.com/drug-design-development-and-therapy-journal 